\title{
Use of an epidural cooling catheter with a closed countercurrent lumen to protect against ischemic spinal cord injury in pigs
}

Akihiro Yoshitake, MD, ${ }^{\text {a }}$ Atsuo Mori, MD, ${ }^{\mathrm{c}}$ Hideyuki Shimizu, MD, ${ }^{\mathrm{a}}$ Toshihiko Ueda, MD, ${ }^{\mathrm{a}}$ Nobuyuki Kabei, PhD, Takashi Hachiya, MD, ${ }^{\mathrm{c}}$ Hideyuki Okano, MD, and Ryohei Yozu, MD ${ }^{\mathrm{a}}$

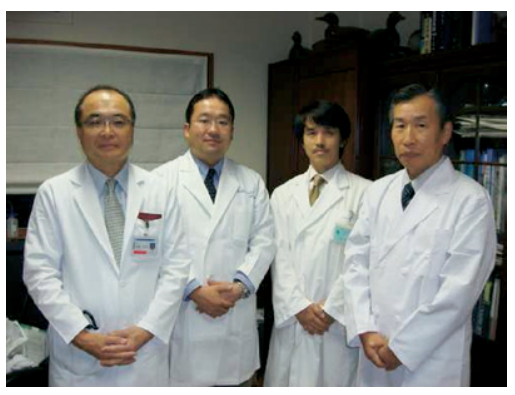

Drs Yozu, Yoshitake, Mori, and Kabei (left to right)
Objective: We developed an epidural cooling catheter containing cold saline solution circulating in an isolated lumen. After placement by a minimally invasive approach, we evaluated protection effect against ischemic spinal cord injury in pigs.

Methods: Fourteen pigs underwent thoracic aortic double clamping for 45 minutes under systemic mild hypothermia $\left(36^{\circ} \mathrm{C}\right)$. Group $\mathrm{A}(\mathrm{n}=7)$ underwent local hypothermia with the cooling catheter. Group B $(n=7)$ underwent catheter placement only, without cooling. Spinal cord somatosensory evoked potentials were recorded to assess electrophysiologic status. Neurologic function was evaluated with a modified Tarlov score.

Results: At aortic crossclamping, spinal temperature in group A $\left(26.5^{\circ} \mathrm{C} \pm 2.4^{\circ} \mathrm{C}\right)$ was significantly lower than that in group $\mathrm{B}\left(35.3^{\circ} \mathrm{C} \pm 0.6^{\circ} \mathrm{C}, P=.0001\right)$. Mean time from aortic crossclamping to onset of potential loss was significantly longer in group A ( $28.4 \pm 6.6$ minutes) than in group B $(18.3 \pm 5.0$ minutes, $P=.007)$. Mean duration of total loss of potentials was significantly shorter in group A $(19.0 \pm 6.7$ minutes) than that in group B $(31.3 \pm 5.9$ minutes, $P=.003)$. Group A showed significantly better neurologic function (mean Tarlov score $4.4 \pm 0.8$ ) than that of group B $(0.1 \pm 0.4, P=.0001)$. Mean total number of intact motor neurons was significantly greater in group A $(24.5 \pm 6.8)$ than that of group B $(9.9 \pm 6.8, P=$ $.0001)$.

Conclusion: By cooling the spinal cord selectively and continuously, the newly designed epidural cooling catheter prevented ischemic injury in a pig model of aortic crossclamping.

From the Departments of Cardiovascular Surgery a and Physiology, ${ }^{\mathrm{b}}$ Keio University School of Medicine, Tokyo, Japan; and the Department of Cardiovascular Surgery, Saitama Cardiovascular and Respiratory Center, Osatogun, Japan.

Supported by the scientific research fund of Saitama prefecture.

Received for publication April 22, 2007; revisions received May 27, 2007; accepted for publication June 11, 2007.

Address for reprints: Akihiro Yoshitake, MD, Department of Cardiovascular Surgery, Keio University School of Medicine, 35 Shinanomachi, Shinjuku, Tokyo, Japan (E-mail: akihiro197253@yahoo.co.jp).

J Thorac Cardiovasc Surg 2007;134:1220-6

$0022-5223 / \$ 32.00$

Copyright $\odot 2007$ by The American Association for Thoracic Surgery

doi:10.1016/j.jtcvs.2007.06.015
$\mathrm{P}$ araplegia has remained a devastating problem associated with thoracoabdominal aneurysm repair. Reported incidence of this complication ranges from $5 \%$ to $8 \%$ in advanced centers. ${ }^{1-4}$ Numerous surgical and pharmacologic interventions have been proposed for prevention, but no single method has succeeded completely in avoiding this dreaded complication.

Systemic hypothermia is a protective measure used frequently against paraplegia associated with aortic surgery. ${ }^{5-7}$ It carries, however, risks of coagulopathy, pulmonary dysfunction, and cardiac arrhythmia.

Regional hypothermia would be a logical alternative approach to minimizing adverse effects of systemic hypothermia while preserving its merits. ${ }^{8}$ Cambria and colleagues ${ }^{9}$ reported a method of regional cooling involving infusion of iced saline solution into the epidural space, demonstrating that infused iced saline solution without drainage from the epidural space could cool the spinal cord selectively. This method raised the major concern of possible associated eleva- 


\section{Abbreviations and Acronyms}

sSEP $=$ spinal cord somatosensory evoked potential

tion in cerebrospinal fluid pressure, however, which would worsen spinal cord perfusion. ${ }^{10}$

In a previous experimental study, we examined the effectiveness of epidural cooling against spinal cord ischemia by simply placing a U-shaped catheter containing cold circulating saline solution in the epidural space. ${ }^{11}$ This protocol required two large skin incisions $(70 \mathrm{~mm})$ and open laminectomy to permit catheter introduction, however, making the procedure too invasive for clinical use.

To overcome this problem, we developed a new cooling catheter with a closed countercurrent lumen. This less cumbersome catheter could be placed with only minimal invasiveness. We investigated its cooling ability and protection against ischemic injury in pigs.

\section{Materials and Methods}

All animals received humane care and treatment in accordance with the "Guide for the Care and Use of Laboratory Animals" (www.nap.edu/catalog/5140.html). Further, both the experimental and animal care protocols were approved by the Animal Care Committee of Saitama Cardiovascular and Respiratory Center, Osatogun, Japan.

\section{Epidural Cooling Catheter and Continuous Cord Cooling System}

The basic concept of our cooling system has been reported previously. ${ }^{11}$ In this study, saline solution was cooled externally to $4{ }^{\circ} \mathrm{C}$ and circulated at a constant rate of $45 \mathrm{~mL} / \mathrm{min}$ by an external pump (AST Co, Ltd, Higashimatsuyama, Japan). Instead of placing a loop catheter bent at the midpoint to form a U shape, we developed a special catheter with a closed countercurrent lumen. This polyurethane cooling catheter (Unitika, Tokyo, Japan), with a 16-gauge outer diameter and $25 \mathrm{~cm}$ length, had a lumen in which cold saline solution could circulate without leakage (Figure 1). The coolant entered the inlet limb of the cooling catheter, passed through the full length of the lumen, and then turned back at the tip of the catheter to be returned to the external units.

\section{Surgical Preparation, Catheter Installation, and Cooling Protocol}

A total of 14 adult pigs weighting 35 to $40 \mathrm{~kg}$ were used. The animals were randomly divided into two equal groups, a regional hypothermia group with cold saline solution circulating through the epidural cooling catheter (group A) and a control group with catheter placement but no circulating cold saline solution (group B).

Swine were anesthetized initially with intramuscular ketamine $(15 \mathrm{mg} / \mathrm{kg})$, intubated, and placed in a right lateral decubitus position on a cooling-warming blanket to maintain mild systemic hypothermia $\left(36^{\circ} \mathrm{C}\right)$. Anesthesia was maintained

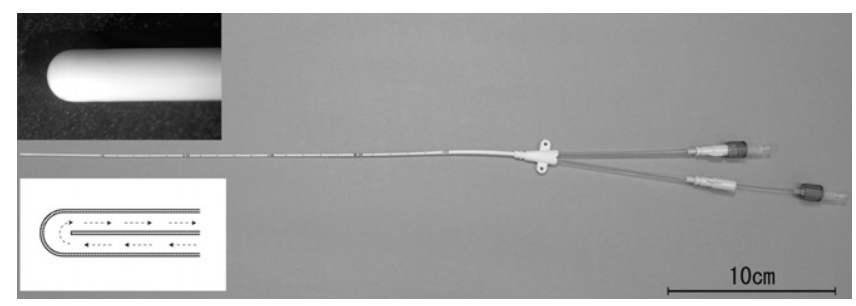

Figure 1. Epidural countercurrent cooling catheter. Saline solution circulates in isolated lumen of cooling catheter, reversing flow direction at tip of catheter without epidural leakage.

with $2.0 \%$ isoflurane added to a mixture of $50 \%$ oxygen and $50 \%$ nitrous oxide.

A $30-\mathrm{mm}$ vertically oriented incision was made $10 \mathrm{~mm}$ lateral to the midline at the level of L3. According to a minimally invasive technique used in orthopedics (METRx-MD; Medtronic Sofamor Danek, Minneapolis, Minn), the caudal part of the superior lamina and the ligamentum flavum were exposed. ${ }^{12}$ Partial caudal hemilaminectomy and removal of the ligamentum flavum were performed to provide entry for the tip of the epidural cooling catheter. Under fluoroscopic guidance, the catheter was advanced carefully into the dorsal epidural space in a cephalad direction until the tip reached the level of Th6. Proximal epidural temperature, distal epidural temperature, and spinal temperature were recorded continuously with thermistor probes placed upon the dorsal dura at Th5 and L4 and in the subarachnoid space at L4. An intrathecal pressure sensor (Johnson \& Johnson, Raynham, Mass) was introduced into the subarachnoid space by means of needle puncture at the L5-L6 interspace.

Left thoracotomy was performed at both the fourth and seventh interspaces. Systemic anticoagulation was provided with heparin sulfate (6-U/kg intravenous bolus). Pressure monitoring catheters were inserted into the right axillary artery, the middle portion of the crossclamped descending thoracic aorta, and the right femoral artery for recording of arterial pressures proximal, central, and distal to the aortic crossclamp, respectively. In both groups swine underwent thoracic double aortic crossclamping for 45 minutes distal to the origin of the left subclavian artery and also just above the diaphragm (Figure 2). During aortic crossclamping, proximal hypertension was controlled with nicardipine hydrochloride ( $4 \mu \mathrm{g} / \mathrm{kg}$ as bolus), After aortic unclamping, blood pressure was restored with phenylephrine hydrochloride ( $3 \mu \mathrm{g} / \mathrm{kg}$ as bolus).

Group A animals underwent epidural cooling with the cooling catheter, beginning 30 minutes before aortic crossclamping and continuing during the 45 minutes of aortic crossclamping. After clamp release, epidural cooling was continued for 30 further minutes to slow the rise of spinal temperature accompanying reperfusion (total epidural cooling 105 minutes). In group B, the epidural catheter was placed in the same fashion, but swine did not undergo epidural cooling at any point in the procedure. After surgery, pigs were extubated and returned to cages with free access to water and food. 


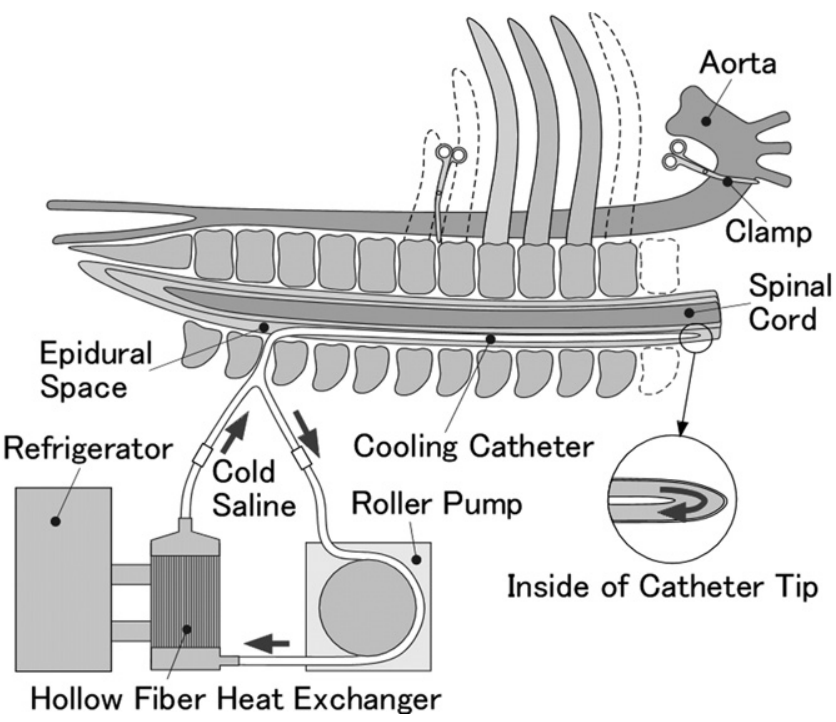

Figure 2. Diagram of continuous cord cooling system in this experimental setting. Circuit is composed of epidural cooling catheter, cooling unit, and circulating pump.

\section{Spinal Cord Somatosensory Evoked Potentials}

We recorded spinal cord somatosensory evoked potentials (sSEPs) directly from the spinal cord. Bipolar electrodes were positioned within the epidural space at the level of L3-L4 for stimulation and at the level of Th5-Th6 for recording. Stimulation parameters included a $0.2-\mathrm{ms}$ pulse duration and a 3- to 5-mA current given at a rate of $5.0 \mathrm{~Hz}$ (Neuropack; Nihon Kohden Corporation, Tokyo, Japan). The sSEPs were recorded on a time base of $30 \mathrm{~ms}$, passing through a bandpass filter of 50 to $1500 \mathrm{~Hz}$. Each recording represented an average of 50 repetitions.

\section{Neurologic Evaluation}

Neurologic status with respect to hindlimb function was assessed at 12, 24, and 48 hours after surgery. A modified Tarlov score was used: 0 for complete paralysis, 1 for minimal movement, 2 for standing with assistance, 3 for standing alone but unable to walk, 4 for weak walking, and 5 for full recovery with normal walking.

\section{Histologic Examination}

After 48 hours, animals were deeply anesthetized and killed with an intravenous overdose of pentobarbital. The spinal cord was removed immediately and fixed in $10 \%$ formaldehyde solution for 2 weeks. For quantitative histopathologic analysis, the spinal cord was divided into five segments, consisting of the three lower thoracic and two lumbar segments. Representative sections of each segment of the spinal cord were stained with hematoxylin and eosin or fluorescent Nissl stain. Thirty-five specimens in each group were reviewed by an independent pathologist. Motor neurons (larger than $50 \mu \mathrm{m}$ in diameter) with normal appearance were counted in each segment.

\section{Statistical Analysis}

We used the Mann-Whitney $U$ test to compare postoperative neurologic status between groups of animals. Other parameters were compared between groups by analysis of variance for repeated measures or by the Student $t$ test as appropriate.

\section{Results}

Baseline rectal temperature, spinal temperature, and epidural temperature were similar between groups A and B. In group $\mathrm{A}$, baseline spinal temperature $\left(35.1{ }^{\circ} \mathrm{C} \pm\right.$ $0.8^{\circ} \mathrm{C}$ ) and baseline epidural temperature at $\mathrm{L} 4$ level $\left(35.2^{\circ} \mathrm{C} \pm 0.8^{\circ} \mathrm{C}\right)$ had fallen significantly, to $26.5^{\circ} \mathrm{C} \pm$ $2.4^{\circ} \mathrm{C}$ and $22.1^{\circ} \mathrm{C} \pm 2.5^{\circ} \mathrm{C}$, respectively, at the time of aortic crossclamping $(P=.0001$; Figure 3$)$. At the conclusion of aortic crossclamping, spinal temperature and epidural temperature at $\mathrm{L} 4$ in group A had fallen further, to $25.4^{\circ} \mathrm{C} \pm 2.2^{\circ} \mathrm{C}$ and $20.8^{\circ} \mathrm{C} \pm 2.2^{\circ} \mathrm{C}$, respectively. Rectal temperature in group A remained essentially constant. A significant difference was evident between spinal and rectal temperatures during aortic crossclamping in group A $(P=.0001)$.

In group B, spinal, epidural, and rectal temperatures all remained constant throughout the procedure. Spinal temperature $\left(35.3^{\circ} \mathrm{C} \pm 0.6^{\circ} \mathrm{C}\right)$, epidural temperature at the levels of T5 $\left(35.5^{\circ} \mathrm{C} \pm 0.6^{\circ} \mathrm{C}\right)$ and $\mathrm{L} 4\left(35.3^{\circ} \mathrm{C} \pm 0.6^{\circ} \mathrm{C}\right)$, and rectal temperature $\left(36.2^{\circ} \mathrm{C} \pm 0.4^{\circ} \mathrm{C}\right)$ at aortic crossclamping all did not differ significantly from one another within group B. No significant difference in rectal temperature between groups A and B was observed during the procedure $(P=$ $.64)$.

The mean aortic pressures during aortic crossclamping at the proximal aorta, the middle segment, and the distal aorta were similar between two groups $(92.5 \pm 13.8 \mathrm{~mm} \mathrm{Hg}, 27.5$ $\pm 5.2 \mathrm{~mm} \mathrm{Hg}$, and $8.7 \pm 3.6 \mathrm{~mm} \mathrm{Hg}$, respectively, in group $\mathrm{A}$, and $90.3 \pm 15.9 \mathrm{~mm} \mathrm{Hg}, 28.2 \pm 4.7 \mathrm{~mm} \mathrm{Hg}$, and $9.6 \pm$ $3.8 \mathrm{~mm} \mathrm{Hg}$, respectively, in group $\mathrm{B}, P=.50, P=.55$, and $P=.25$, respectively).

\section{Intrathecal Pressure}

Intrathecal pressure was similar between groups during aortic crossclamping (group A $5.0 \pm 1.6 \mathrm{~mm} \mathrm{Hg}$, group B 5.3 $\pm 1.6 \mathrm{~mm} \mathrm{Hg}, P=.37$ ). No significant elevation of intrathecal pressure was detected at aortic unclamping in group A $(5.5 \pm 1.2 \mathrm{~mm} \mathrm{Hg})$ relative to group B $(5.8 \pm 1.8 \mathrm{~mm}$ $\mathrm{Hg} ; P=.94)$.

\section{Spinal Cord Somatosensory Evoked Potentials}

In group A, epidural cooling before aortic crossclamping significantly prolonged latency of sSEPs $(2.47 \pm 0.37 \mathrm{~ms}$ at baseline vs $3.24 \pm 0.50 \mathrm{~ms}$ at aortic crossclamping, $P=$ $.01)$ and reduced their amplitude $(35.5 \pm 6.6 \mu \mathrm{V}$ at baseline vs $12.5 \pm 5.4 \mu \mathrm{V}$ at aortic crossclamping, $P=.0001)$. No 


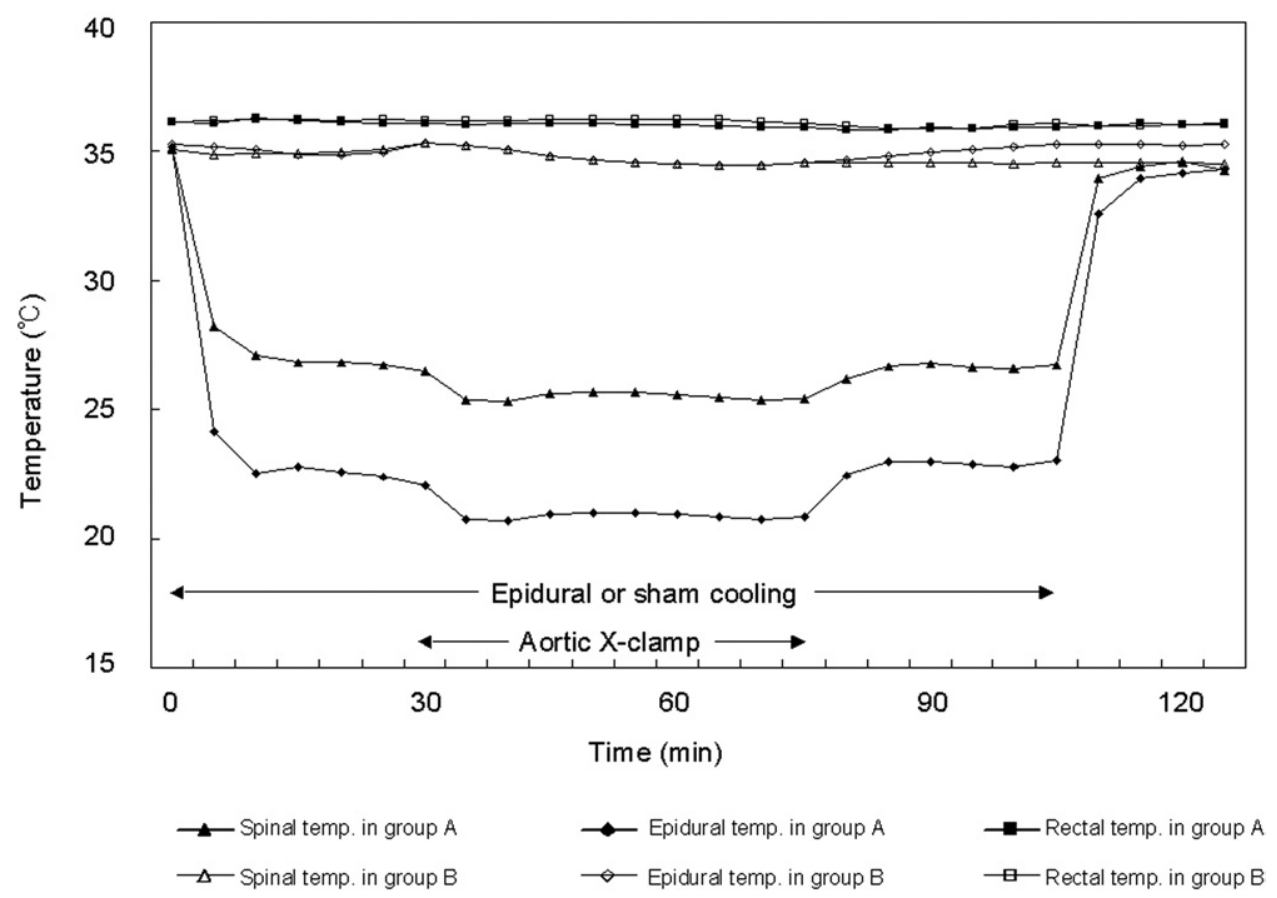

Figure 3. Changes in spinal, epidural (L4), and rectal temperatures during procedure. Filled triangles, filled diamonds, and filled squares, respectively, represent spinal, epidural, and rectal temperatures (temp) in cooling group (group A). Open triangles, open diamonds, and open squares, respectively, represent spinal, epidural, and rectal temperatures in control group (group B). X-clamp, Crossclamping.

pig showed abolition of sSEP waveforms as a result of epidural cooling itself.

Mean time from aortic crossclamping to onset of sSEP loss was significantly longer in group A than group B. Mean total time of sSEP loss and SSEP recovery time were significantly shorter in group A than in group B (Table 1).

The ratios of final amplitude of sSEPs to baseline amplitude (final amplitude/baseline) were $0.98 \pm 0.12$ in group $\mathrm{A}$ and $1.14 \pm 0.31$ in group B $(P=.27)$. The ratios of final latency to baseline latency were $1.04 \pm 0.03$ in group $\mathrm{A}$ and $1.05 \pm 0.04$ in group B $(P=.65)$.

\section{Recovery of Motor Function}

All 14 animals tolerated the period of aortic occlusion, survived the 48 -hour recovery period after operation, and

TABLE 1. Loss and recovery of spinal cord somatosensory evoked potentials by group

\begin{tabular}{lrrr}
\hline & & $P$ value \\
\hline Interval to potential loss (min) & $28.4 \pm 6.6$ & $18.3 \pm 5.0$ & .007 \\
Total loss time (min) & $19 \pm 6.7$ & $31.3 \pm 5.9$ & .003 \\
Recovery time (min) & $2.4 \pm 1.1$ & $4.6 \pm 1.8$ & .021 \\
\hline
\end{tabular}

Data are expressed as mean \pm SD. then underwent final neurologic evaluation. Group A animals showed significantly better neurologic scores at every point after operation than did group B $(P=.001$, Table 2).

\section{Histologic Examination}

Representative histologic sections from lumbar and thoracic segments of the cord are shown in Figure 4. In group A, motor neurons had a nearly normal appearance, with minimal eosinophilic change in the cytoplasm. Group B motor

TABLE 2. Neurologic outcome

\begin{tabular}{|c|c|c|c|c|c|c|}
\hline \multirow{2}{*}{$\begin{array}{l}\text { Tarlov } \\
\text { score }\end{array}$} & \multicolumn{3}{|c|}{ Cooling $(n=7)$} & \multicolumn{3}{|c|}{ Control $(n=7)$} \\
\hline & $12 \mathrm{~h}$ & $24 \mathrm{~h}$ & $48 \mathrm{~h}$ & $12 \mathrm{~h}$ & $24 \mathrm{~h}$ & $48 \mathrm{~h}$ \\
\hline 5 & 3 & 4 & 4 & 0 & 0 & 0 \\
\hline 4 & 2 & 3 & 2 & 0 & 0 & 0 \\
\hline 3 & 2 & 0 & 1 & 0 & 0 & 0 \\
\hline 2 & 0 & 0 & 0 & 0 & 0 & 0 \\
\hline 1 & 0 & 0 & 0 & 1 & 1 & 1 \\
\hline 0 & 0 & 0 & 0 & 6 & 6 & 6 \\
\hline
\end{tabular}



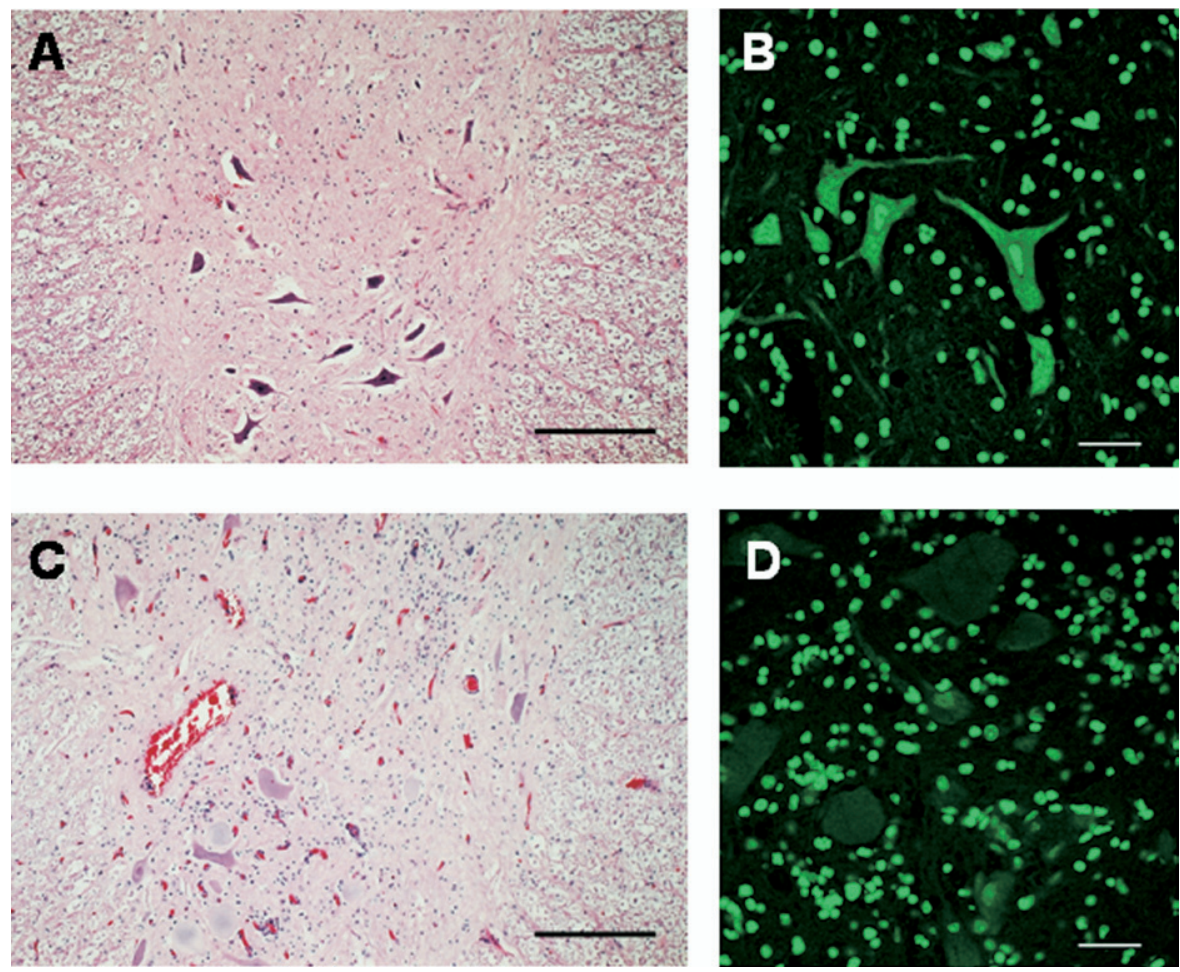

Figure 4. Representative photomicrographs of anterior horn of spinal cord sections. $A$, Section from group $A$ stained with hematoxylin and eosin (bar represents $250 \mu \mathrm{m}$ ). Photomicrograph demonstrates a normal appearance. $B$, Section from group A after fluorescent Nissl staining (bar represents $50 \mu \mathrm{m}$ ). Nissl granules were clearly seen in large motor neurons. $C$, Section from group B stained with hematoxylin and eosin. Photomicrograph demonstrates severe, extensive gray matter necrosis (bar represents $250 \mu \mathrm{m}$ ). $D$, section from group B after fluorescent Nissl staining. Nissl granules were not identified in shrunken motor neurons (bar represents $50 \mu \mathrm{m}$ ).

neurons showed acute necrotic changes. Degenerating neurons were swollen or shrunken.

Significantly, a greater number of large motor neurons could be seen in the gray matter of all segments in group A than in corresponding segments in group B. Mean total number of intact motor neurons was significantly greater in group A (24.5 \pm 6.8$)$ than in group B $(9.9 \pm 6.8, P=$ .0001).

\section{Discussion}

To decrease invasiveness of catheter introduction, we redesigned the cooling catheter to contain a closed circuit passing through it in a countercurrent manner. The catheter is small enough to be placed with a minimally invasive procedure, which is an advance over the larger U-loop catheter used in our previous report. Furthermore, we also used thoracic aortic double crossclamping for 45 minutes, whereas we had made only single aortic crossclamping for 30 minutes in our previous study. We believe that our cooling method has proved to be an additional protective measure against ischemic spinal cord injury in a situation similar to that of clinical aortic surgery. We believe that the changed shape of the catheter may represent significant progress toward accomplishing the percutaneous introduction.

The bones and ligaments of the spinal canal produce less heat than muscle and abdominal organs. Aided by this unique physiologic anatomy, our small cooling catheter could cool the spinal cord selectively, effectively, and continuously. We induced mild systemic hypothermia of $36^{\circ} \mathrm{C}$ with a cooling-warming blanket and maintained the temperature during surgery, changing the blanket mode (cooling or warming) according to the situation. In pigs, under normothermic conditions $\left(38^{\circ} \mathrm{C}\right), 45 \mathrm{~min}-$ utes of double thoracic aortic clamping without distal perfusion induces metabolic acidosis as a result of severe ischemia of the abdominal organs and lower limbs, which often leads to death.

From the standpoint of thermal kinetics, the spinal cord, like other organs has three major sources of heat. 
First is incoming blood flow, which carries not only oxygen and glucose but also heat. Second is the surrounding bone and connective tissue, which provides some insulation as mentioned previously but still produces and transmits some heat to the spinal cord by heat conduction. Third is the spinal cord itself, which produces heat biochemically by its own metabolism. When the spinal cord is cooled with an epidural catheter, an equilibrium develops involving balance between the amount of heat removed by proximity to the cooling catheter and heat from these three sources.

In our experimental group cooled by the epidural cooling system, sSEP disappearance after clamping occurred later than in the control group, and the regionally cooled pigs fully regained essentially baseline sSEP characteristics immediately after release of the clamp. Accordingly, the total time of sSEP loss was significantly longer in the control group than in the cooling group. Our neurologic results in this experimental study were consistent with the clinical observations of Grabitz and coworkers. ${ }^{13}$ Monitoring of the sSEPs surveys conduction of impulses from afferent nerves as they ascend in the posterior column. ${ }^{14}$ Axons are considered more resistant to ischemic stress than are neuronal cell bodies, particularly in the motor system. ${ }^{15}$ Forty-five minutes of ischemia may not be long enough for all axons to lose function; however, such time might be sufficient for neuronal cell bodies to initiate irreversible processes leading to neuronal death. ${ }^{16}$

In a model of aortic double clamping, we demonstrated that our newly designed catheter could protect the spinal cord against ischemia for as long as 45 minutes. Because pigs are considered to show less tolerance than human beings of spinal cord ischemia, spinal cord protection against ischemic stress induced by 45 minutes of aortic double clamping in swine indicates considerable promise for efficacy in the clinical setting.

In clinical surgery, systemic moderate hypothermia induced by distal perfusion from the left atrium is commonly used. This lowers the temperature of the blood flow into the spinal cord, and additional use of our local cooling might further decrease the temperature of the spinal cord during aortic crossclamping, leading to more protection against spinal cord injury.

Clinically, sSEPs and motor evoked potentials are frequently monitored. ${ }^{17}$ As long as the temperature of spinal cord is kept above $25^{\circ} \mathrm{C}$, sSEPs and motor evoked potentials do not disappear as a result of the combined hypothermia and thus still could be a good indication of ischemic stress on the spinal cord.

Because our cooling catheter does not increase intrathecal pressure, the combination with cerebrospinal fluid drainage with another catheter into intrathecal space may lower the cerebrospinal fluid pressure during aortic crossclamping. The combined use may be a promising strategy to prevent paraplegia.

Drawbacks of our method include requirements for a small skin incision and a single-level laminectomy to place the cooling catheter. Further refinements of catheter introduction may permit wholly percutaneous placement in a fashion similar to introduction of a catheter for epidural anesthesia.

In conclusion, we have demonstrated in pigs that a newly designed catheter could cool the spinal cord to $9.7^{\circ} \mathrm{C}$ below the rectal temperature during double aortic crossclamping, without elevating cerebrospinal fluid pressure. Protective effects against ischemic spinal cord injury have been shown. We believe that our epidural cooling catheter may become a practical aid in avoiding paraplegia associated with aortic surgery, especially when used in combination with other protective techniques.

We express special thanks to Masanori Yoshida, $\mathrm{PhD}$, Ryoichi Tashiro, PhD, Takashi Kimura, Shinobu Negishi, Ryota Wada, Norio Koike, Tatsuya Takagi, Yusuke Matsuda, Shinji Matsuo, and Setsuko Misawa for their technical assistance.

\section{References}

1. Svensson LG, Crawford ES, Hess KR, Coselli JS, Safi HJ. Experience with 1509 patients undergoing thoracoabdominal aortic operations. $J$ Vasc Surg. 1993; 17:357-70.

2. Cambria RP, Davison JK, Zannetti S, L'Italian G, Atamian S. Thoracoabdominal aneurysm repair: perspectives over a decade with the clamp-and-sew thchnique. Ann Surg. 1997;226:294-305.

3. Coselli JS, LeMaire SA, Conklin LD, Köksoy C, Schmittling ZC. Morbidity and mortality after extent II thoracoabdominal aortic aneurysm repair. Ann Thorac Surg. 2002;73:1107-15.

4. Griepp RB, Ergin MA, Galla JD, Lansman S, Khan N, Quintana C, et al. Looking for the artery of Adamkiewicz: a quest to minimize paraplegia after operations for aneurysms of the descending thoracic and thoracoabdominal aorta. J Thorac Cardiovasc Surg. 1996;112: 1202-15.

5. Crawford ES, Coselli JS, Safi HJ. Partial cardiopulmonary bypass, hypothermic circulatory arrest, and posterolateral exposure for thoracic aortic aneurysm operation. J Thorac Cardiovasc Surg. 1987;94: 824-7.

6. Kouchoukos NT, Masetti P, Rokkas CK, Murphy SF. Hypothermic cardiopulmonary bypass and circulatory arrest for operations on the descending thoracic and thoracoabdominal aorta. Ann Thorac Surg. 2002;74:S1885-8

7. Rokkas CK, Cronin CS, Nitta T, Helfrich LR, Lobner DC, Choi DW, et al. Profound hypothermia for spinal cord protection in operations on the descending thoracic and thoracoabdominal aorta. Semin Thorac Cardiovasc Surg. 1998;10:57-60.

8. Tabayashi K, Niibori K, Konno H, Mohri H. Protection from postischemic spinal cord injury by perfusion cooling of the epidural space. Ann Thorac Surg. 1993;56:494-8.

9. Cambria RP, Clouse WD, Davison JK, Dunn PF, Corey M, Dorer D. Thoracoabdominal aneurysm repair: results with 337 operations performed over a 15-year interval. Ann Surg. 2002;236:471-9.

10. Meylaerts SA, Kalkman CJ, Haan P, Porsius M, Jacobs MJ. Epidural versus subdural spinal cord cooling: cerebrospinal fluid temperature and pressure changes. Ann Thorac Surg. 2000;70:222-7.

11. Mori A, Ueda T, Hachiya T, Kabei N, Okano H, Yozu R, et al. An epidural cooling catheter protects the spinal cord against ischemic injury in pigs. Ann Thorac Surg. 2005;80:1829-34. 
12. Johnson MR, Tomes DJ, Treves JS, Leibrock LG. Minimally invasive implantation of epidural spinal cord neurostimulator electrodes by using a tubular retractor system. J Neurosurg. 2004;100:1119-21.

13. Grabitz K, Sandmann W, Stuhmeier K, Mainzer B, Godehardt E, Ohle $\mathrm{B}$, et al. The risk of ischemic spinal cord injury in patients undergoing graft replacement for thoracoabdominal aortic aneurysms. J Vasc Surg. 1996;23:230-40

14. Galla JD, Ergin MA, Lansman SL, Cullough JN, Nguyen KH, James DS, et al. Use of somatosensory evoked potentials for thoracic and thoracoabdominal aortic resection. Ann Thorac Surg. 1999:67;194752 .
15. Lips J, Haan P, Bouma GJ, Jacobs MJ, Kalkman CJ. Delayed detection of motor pathway dysfunction after selective reduction of thoracic spinal cord blood flow in pigs. J Thorac Cardiovasc Surg. 2002;123: 531-8.

16. Sakurai M, Hayashi T, Abe K, Sadahiro M, Tabayashi K. Delayed and selective motor neuron death after transient spinal cord ischemia: a role of apoptosis? J Thorac Cardiovasc Surg. 1998:115;1310-4.

17. Strauch JT, Lauten A, Spielvogel D, Rinke S, Zhang N, Weisz D, et al. Mild hypothermia protects the spinal cord from ischemic injury in a chronic porcine model. Eur J Cardiothorac Surg 2004;25:708-15.

\section{Interactive eLearning Activities http://learning.ctsnet.org}

The Joint Council on Thoracic Surgery Education was pleased to introduce a series of unique eLearning activities to CTSNet users at the AATS annual meeting in Philadelphia. Sponsored by several cardiothoracic surgical groups, this exciting new educational tool contains narrated videos of actual surgical procedures followed by a series of questions and an evaluation to earn Continuing Medical Education credit.

* Diagnosis and Management of Complications of Mitral Valve Repair

* Off Pump Coronary Artery Bypass

* OPCAB Debriefing

* Pediatric Cardiopulmonary Bypass Emergency Situations

\section{Experience these new educational tools today and provide us with your feedback. Go to: http://learning.ctsnet.org}

William E. Baumgartner, Chair

Joint Council on Thoracic Surgery Education

$$
\text { Sponsored By: }
$$

American Association for Thoracic Surgery

The Society of Thoracic Surgeons

European Association for Cardio-Thoracic Surgery

Children's Memorial Hospital 